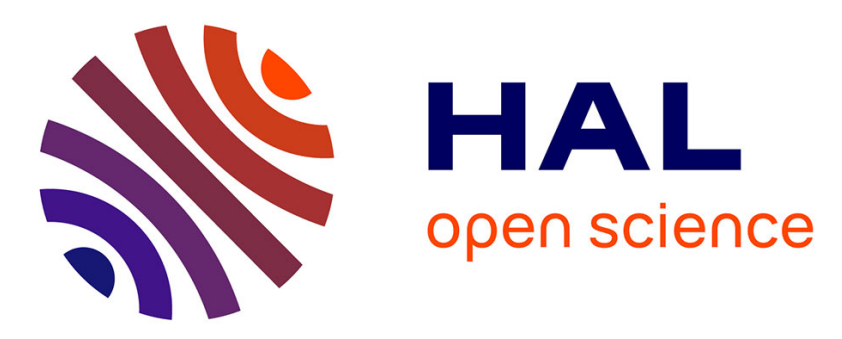

\title{
General oxidative stress during doxorubicin-induced cardiotoxicity in rats: absence of cardioprotection and low antioxidant efficiency of alpha-lipoic acid.
}

Steliana Ghibu, Stéphanie Delemasure, Carole Richard, Jean-Claude Guilland, Laurent Martin, Ségolène Gambert, Luc Rochette, Catherine Vergely

\section{To cite this version:}

Steliana Ghibu, Stéphanie Delemasure, Carole Richard, Jean-Claude Guilland, Laurent Martin, et al.. General oxidative stress during doxorubicin-induced cardiotoxicity in rats: absence of cardioprotection and low antioxidant efficiency of alpha-lipoic acid.. Biochimie, 2012, 94 (4), pp.932-9. 10.1016/j.biochi.2011.02.015 . hal-00828304

\section{HAL Id: hal-00828304 \\ https://u-bourgogne.hal.science/hal-00828304}

Submitted on 30 May 2013

HAL is a multi-disciplinary open access archive for the deposit and dissemination of scientific research documents, whether they are published or not. The documents may come from teaching and research institutions in France or abroad, or from public or private research centers.
L'archive ouverte pluridisciplinaire HAL, est destinée au dépôt et à la diffusion de documents scientifiques de niveau recherche, publiés ou non, émanant des établissements d'enseignement et de recherche français ou étrangers, des laboratoires publics ou privés. 


\section{Elsevier Editorial System(tm) for Biochimie Manuscript Draft}

\section{Manuscript Number:}

Title: General oxidative stress during doxorubicin-induced cardiotoxicity in rats: absence of cardioprotection and low antioxidant efficiency of alpha-lipoic acid

Article Type: Research Paper

Section/Category: Regular issue

Keywords: doxorubicin, alpha-lipoic acid, rat hearts, oxidative stress, cardioprotection

Corresponding Author: Pr. Catherine Vergely, PharmD, PhD

Corresponding Author's Institution: University of Burgundy

First Author: Stéliana Ghibu, PharmD, PhD

Order of Authors: Stéliana Ghibu, PharmD, PhD; Stéphanie Delemasure, PharmD, PhD; Carole Richard, MD; Jean-Claude Guillland, PhD; Laurent Martin, MD, PhD; Luc Rochette, PharmD, PhD; Catherine Vergely, PharmD, PhD

\section{Manuscript Region of Origin: FRANCE}

Abstract: To evaluate the effects of alpha-lipoic acid (AL) in a model of doxorubicin (DOX)-induced cardiotoxicity, male Wistar rats were treated with DOX $(1 \mathrm{mg} / \mathrm{kg} / \mathrm{d} ; 10 \mathrm{~d})$ in addition or not with AL $(50 \mathrm{mg} / \mathrm{kg} / \mathrm{d} ; 15 \mathrm{~d})$. Plasma oxidative stress was determined by hydroperoxides $(\mathrm{ROOH})$ and ascorbyl radical/ascorbate ratio. Two months after, heart's functional parameters were determined in vivo by catheterization and cardiac oxidative stress by malonedialdehyde (MDA) and 02*- (dihydroethidium fluorescence) tissue content.

After two months, body weight was higher in DOX-AL group than in DOX $(+16 \%)$, but was due to ascites. Histological liver alterations were observed in DOX and DOX-AL groups. Plasma ROOH concentrations decreased after 10 days of AL treatment, but were greater in DOX and DOX-AL groups. After two months, a decrease $(-27 \%)$ in cardiac contractility index and a cardiac hypertrophy were observed in DOX and DOX-AL. These dysfunctions were associated with 1) a reduction in plasma ascorbate levels and an increase in ascorbyl/ascorbate ratio and 3) an increase in cardiac tissue MDA and $02{ }^{*}$ - content.

In conclusion, a cumulative dose of $10 \mathrm{mg} / \mathrm{kg}$ doxorubicin induced liver and heart functional alterations associated with plasma and cardiac oxidative stress. The co-administration of the antioxidant compound AL seemed to accentuate hepatic dysfunction.

Suggested Reviewers: Christophe RIbuot PharmD, PhD Christophe.Ribuot@ujf-grenoble.fr

Already published work on cardiotoxicity of anthracyclines

Daniel Lamontagne

daniel.lamontagne@u-montreal.ca

Already worked on anthracycline's cardiotoxicity 
Opposed Reviewers: 
LABORATOIRE DE

PHYSIOPATHOLOGIE ET PHARMACOLOGIE

CARDIOVASCULAIRES EXPERIMENTALES

7 Bd Jeanne d'Arc

BP 87900

21079 DIJON Cedex

Pr. Catherine VERGELY

Tél. : 0380393460

Fax : 0380393293

e.mail : cvergely@u-bourgogne.fr
UNIVERSITE DE BOURGOGNE

FACULTES DE MEDECINE

ET DE PHARMACIE

Dijon, October $27^{\text {th }} 2010$

Dear Editor,

On behalf of my co-authors, I am submitting the enclosed material for possible publication in BIOCHIMIE.

"General oxidative stress during doxorubicin-induced cardiotoxicity in rats: absence of cardioprotection and low antioxidant efficiency of alpha-lipoic acid."

S. Ghibu, S. Delemasure, C. Richard, J.-C. Guilland, L. Martin, L. Rochette and C. Vergely

The manuscript, or part of it, neither has been published (except in the form of abstract or as part of a published lecture or academic thesis) nor is currently under consideration for publication by any other journal.

All the co-authors have read the manuscript and approved its submission to BIOCHIMIE. Tacitly or explicitly, the publication is approved by the responsible authorities where the work was carried out. If this article is accepted, it will not be published elsewhere including electronically in the same form, in English or in any other language without the written consent of the copyright-holder.

Yours sincerely,

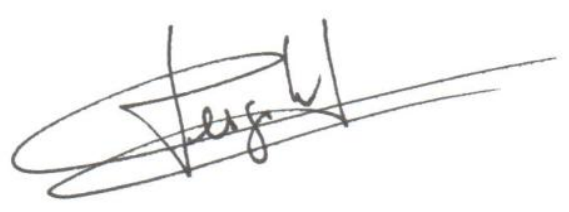

Pr. Catherine VERGELY 
LABORATOIRE DE

PHYSIOPATHOLOGIE ET PHARMACOLOGIE

CARDIOVASCULAIRES EXPERIMENTALES

7 Bd Jeanne d'Arc

BP 87900

21079 DIJON Cedex

Pr. Catherine VERGELY

Tél. : 0380393460

Fax : 0380393293

e.mail : cvergely@u-bourgogne.fr
UNIVERSITE DE BOURGOGNE

FACULTES DE MEDECINE

ET DE PHARMACIE

Dijon, October $27^{\text {th }} 2010$

Article Title: "General oxidative stress during doxorubicin-induced cardiotoxicity in rats: absence of cardioprotection and low antioxidant efficiency of alpha-lipoic acid."

Authors: S. Ghibu, S. Delemasure, C. Richard, J.-C. Guilland, L. Martin, L. Rochette and C. Vergely

All the co-authors have read the manuscript and approved its submission to BIOCHIMIE.

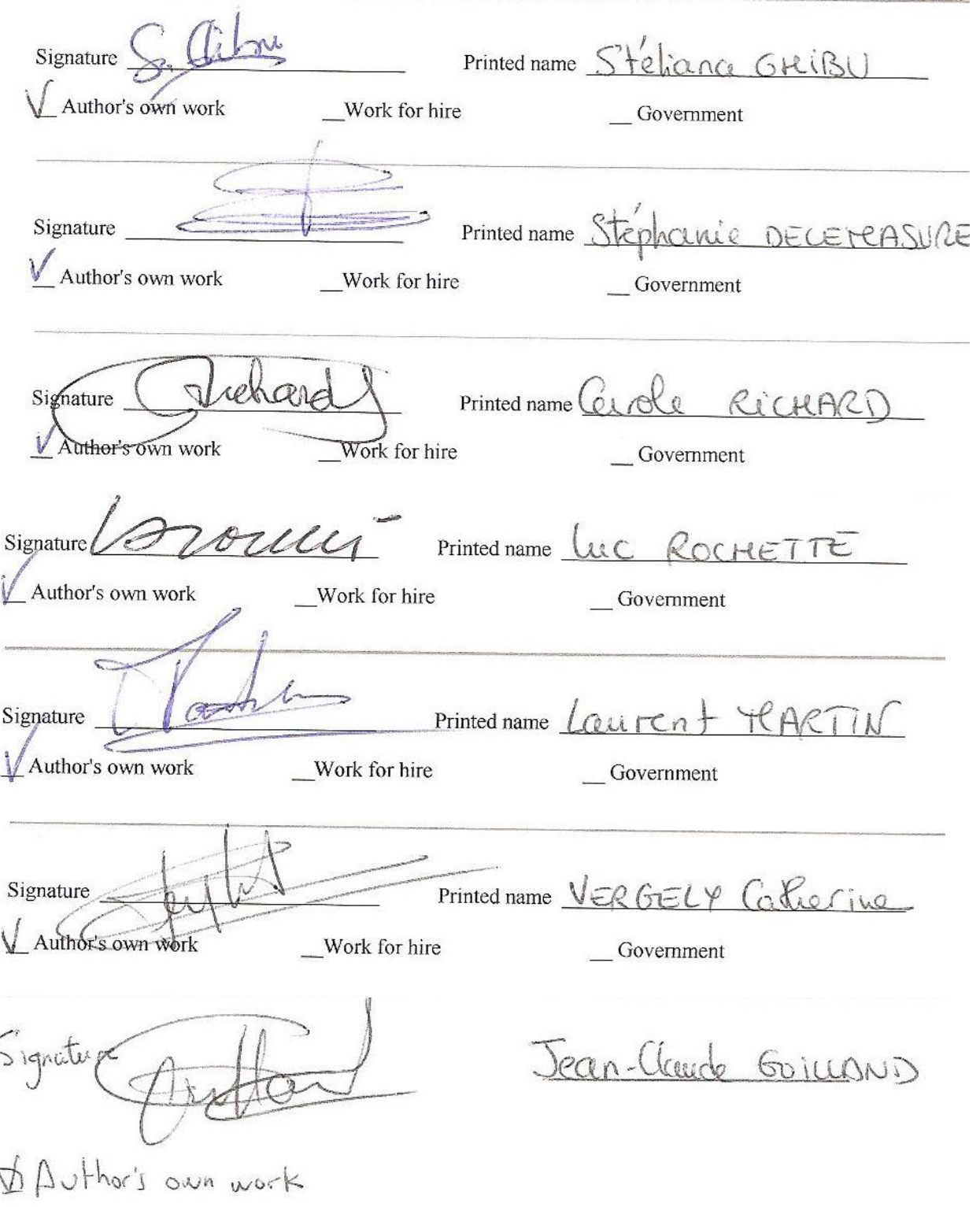




\section{Abstract:}

To evaluate the effects of alpha-lipoic acid (AL) in a model of doxorubicin (DOX)induced cardiotoxicity, male Wistar rats were treated with DOX $(1 \mathrm{mg} / \mathrm{kg} / \mathrm{d} ; 10 \mathrm{~d})$ in addition or not with AL $(50 \mathrm{mg} / \mathrm{kg} / \mathrm{d} ; 15 \mathrm{~d})$. Plasma oxidative stress was determined by hydroperoxides $(\mathrm{ROOH})$ and ascorbyl radical/ascorbate ratio. Two months after, heart's functional parameters were determined in vivo by catheterization and cardiac oxidative stress by malonedialdehyde (MDA) and $\mathrm{O}_{2}{ }^{\bullet-}$ (dihydroethidium fluorescence) tissue content.

After two months, body weight was higher in DOX-AL group than in DOX $(+16 \%)$, but was due to ascites. Histological liver alterations were observed in DOX and DOX-AL groups. Plasma ROOH concentrations decreased after 10 days of AL treatment, but were greater in DOX and DOX-AL groups. After two months, a decrease (-27\%) in cardiac contractility index and a cardiac hypertrophy were observed in DOX and DOX-AL. These dysfunctions were associated with 1) a reduction in plasma ascorbate levels and an increase in ascorbyl/ascorbate ratio and 3) an increase in cardiac tissue MDA and $\mathrm{O}_{2}{ }^{\bullet-}$ content.

In conclusion, a cumulative dose of $10 \mathrm{mg} / \mathrm{kg}$ doxorubicin induced liver and heart functional alterations associated with plasma and cardiac oxidative stress. The coadministration of the antioxidant compound AL seemed to accentuate hepatic dysfunction.

Keywords: doxorubicin, alpha-lipoic acid, rat hearts, oxidative stress, cardioprotection, anthracyclines 
Highlights:

Doxorubicin induces cardiotoxicity via oxidative stress-mediated injury

Lipoic acid and its metabolite dihydrolipoic acid are potent antioxidants both in vitro and in vivo Some antioxidants may exert pro-oxidant capacities in certain conditions

Lipoic acid was unable to decrease oxidative stress in doxorubicin-treated rats

Moreover lipoic acid seemed to accentuate cardiac and hepatic injury 
Abbreviations : AFR, ascorbyl free radical; AL, alpha-lipoic acid; ANOVA, analysis of variance; AU, arbitrary units; DHE, dihydroethidium; DHLA, dihydrolipoic acid; DOX, Doxorubicin; ESR, electron spin resonance; HR, heart rate; Ht, hematocrit; LVDP, left ventricular developed pressure; LVEDP, left ventricular end-diastolic pressure; LVESP, left ventricular end-systolic pressure; $\mathrm{O}_{2}{ }^{\bullet-}$, superoxide anion; $\mathrm{ROOH}$, hydroperoxides; TBARs, thiobarbituric acid reactive substances

\section{General oxidative stress during doxorubicin-induced cardiotoxicity in rats: absence of cardioprotection and low antioxidant efficiency of alpha-lipoic acid} Steliana Ghibu ${ }^{\mathrm{a}}$, Stéphanie Delemasure ${ }^{\mathrm{b}}$, Carole Richard ${ }^{\mathrm{b}}$, Jean-Claude Guilland ${ }^{\mathrm{b}}$, Laurent Martin $^{\mathrm{c}}$, Luc Rochette ${ }^{\mathrm{b}}$, Catherine Vergely ${ }^{\mathrm{b}} *$

${ }^{a}$ Department of Pharmacology, Physiology and Physiopathology; Faculty of Pharmacy, University of Medicine and Pharmacy, Cluj-Napoca, Romania

${ }^{b}$ Laboratoire de Physiopathologie et Pharmacologie Cardiovasculaires Expérimentales, Université de Bourgogne, IFR Santé-STIC 100, Facultés de Médecine et Pharmacie, 7 bd Jeanne d'Arc, 21000 Dijon, France

${ }^{c}$ Department of Pathology, Pôle Technique de Biologie, Centre Hospitalier Universitaire, 2 rue Angélique Ducoudray 21000 Dijon, France

* Corresponding author: Catherine VERGELY; phone: (+33) 3803934 60; fax: (+33) 38039 32 93; email: cvergely@bourgogne.fr

Running title: Lipoic acid and doxorubicin cardiotoxicity

\section{Conflict of Interest Statement:}

The authors declare to have no personal, financial or other relationships with other people or organizations within 3 years of beginning the work submitted that could inappropriately influence, or be perceived to influence, the work submitted.

\section{Funding Source Statement}

This work was supported by grants from the French Ministry of Research, the Conseil Régional de Bourgogne, the Association de Cardiologie de Bourgogne and the Agence Universitaire de la Francophonie (AUF). 


\section{Introduction}

Doxorubicin is an anthracycline anti-neoplasic drug used in the treatment of a wide range of solid tumors and of leukemia in children and adults. Despite its good therapeutic results, the clinical use of doxorubicin during chemotherapy is limited by the development of acute, subacute, early chronic or late chronic cardiotoxicity [1-2]. Cardiac alterations become more obvious several years after the end of the treatment and may occur as a dilated cardiomyopathy leading to congestive heart failure [3-6].

Despite a large amount of research on this subject, the molecular mechanisms involved in chronic anthracycline cardiotoxicity remain a major topic of discussion. Several aspects of this phenomenon, such as apoptosis, alteration of iron and calcium homeostasis have been described but the exact mechanism has not yet been fully understood. Indeed, oxidative stress is believed to represent an important pathway involved in the cardiac side-effects induced by anthracycline therapy [7-9]. It is widely known that superoxide anion free radical $\left(\mathrm{O}_{2}{ }^{-}\right)$is generated during the "redox cycling" of anthracycline or after oxido-reduction processes taking place inside the anthracycline-iron complex. Then, $\mathrm{O}_{2}{ }^{--}$is driven to hydroxyl radical $\left(\mathrm{HO}^{\circ}\right)$ in the presence of transition metals or forms peroxinitrite $\left(\mathrm{ONOO}^{-}\right)$in the presence of nitric oxide $\left({ }^{\circ} \mathrm{NO}\right)$, both of them being strong oxidants which can induce cellular injury [9-11].

Along with preventive measures implemented to limit anthracycline-induced cardiotoxicity [4, 12], several antioxidants molecules have been tested for their potential cardioprotective effects in different experimental models in the last forty years. Despite some beneficial results of vitamin E, vitamin A, N-acetyl cysteine, probucol [13], carvedilol, glutathione, superoxide dismutase, catalase, none of these antioxidants have proved to be of a clear benefit to humans [14-15]. The only drug presently approved for use in clinical practice to reduce cardiac side-effects of anthracyclines is dexrazoxane (Cardioxane ${ }^{\circledR}$ ) [15-17], a prodrug of ethylenediamine tetra-acetic acid which chelates intracellular iron [15, 18-19].

In this context, it seems interesting to evaluate the possible cardioprotective effects of alpha-lipoic acid (AL). Alpha-lipoic acid or thioctic acid (6,8-dithio-octanoic) is a thiol compound with antioxidant properties which can be found in plants and animals. AL is able to scavenge free radicals $\left(\mathrm{HO}^{\circ}, \mathrm{HClO},{ }^{1} \mathrm{O}_{2}\right.$ ), chelate transition metals (iron and copper) or regenerate oxidized forms of antioxidants (vitamin E, vitamin C and glutathione) [20-21]. AL is both a water- and lipid-soluble molecule, property which allows it to concentrate in cellular and 
extracellular environments. Exogenous AL is rapidly absorbed from the diet, and is reduced intracellularly to dihydrolipoic acid (DHLA), the most active form of the substance [22-23]. Its low negative redox potential $(0.32 \mathrm{~V})$ gives to AL/DLHA a strong reducing character. A number of studies have reported the beneficial effects of AL in diabetes mellitus, insulin resistance [24], diabetic neuropathy [25-26], vascular inflammation [27-28], erythrocytes membrane stability [29] and neurodegenerative diseases [23, 30], all these effects being associated with its antioxidants properties. However, few recent studies have mentioned the pro-oxidant potential of AL and DHLA depending on the type of oxidative stress and the physiological conditions [31-32].

In this general context, the aims of our work were: 1) to create a model of chronic cardiotoxicity induced by doxorubicin in rats, 2) to confirm the physiopathological role of oxidative stress in cardiac injury and 3 ) to assess the impact of a treatment with alpha-lipoic acid $(\mathrm{AL})$ in these experimental conditions.

\section{Materials and methods}

\subsection{Animals and experimental protocol}

The local ethic committee approved the experimental protocol and the investigators complied with authorization 6007 from the French government, which agrees with the EC Directive 86/609:EEC for animal experiments. For the purpose of our study, 72 male Wistar rats (Charles-River, L'Abresle, France; 300-350 g at the beginning of the experiment) were divided into 4 groups.

In control group $(\mathrm{C}, \mathrm{n}=18)$, rats received saline solution: $1 \mathrm{ml} / \mathrm{kg} /$ day intraperitoneally (i.p.) during 15 days; from day -5 (D-5) to day 9 (D9, Fig. 1).

In the doxorubicin-treated group (DOX, $\mathrm{n}=18$ ), rats were injected i.p with $1 \mathrm{mg} / \mathrm{kg} / \mathrm{day}$ doxorubicin (Adriamycin ${ }^{\circledR}$, Pfizer, Paris, France) during 10 days, from day 0 (D0) to D9. A total dose of $10 \mathrm{mg} / \mathrm{kg}$ doxorubicin was administered over a 10-days period (Fig. 1).

In the lipoic acid-treated group (AL), rats were injected i.p. with $50 \mathrm{mg} / \mathrm{kg} / \mathrm{day}$ alphalipoic acid (Thiogamma 600®, Wörwarg Pharma, Germany) during 15 days, from D-5 to D9. A total dose of $750 \mathrm{mg} / \mathrm{kg}$ lipoic acid was administered over a 15-days period (Fig. 1). 
In the last group (DOX-AL, $\mathrm{n}=18$ ), rats were treated with both doxorubicin and alphalipoic acid at the same dose as the two previous groups. During the firsts 5 days, the rats were injected with alpha-lipoic acid (50 mg/kg/day), then was given a combined therapy: doxorubicin (1 mg/kg/day) and alpha-lipoic acid, over 10 days (Fig. 1).

The rats were sacrificed one month (D40; Series I, $\mathrm{n}=36$ ) or two months (D70; Series II, $\mathrm{n}=32)$ after the end of the treatment. Each series was composed of 4 groups of animals $(\mathrm{C}: \mathrm{n}=$ 9; DOX: n=9; AL: n = 9; DOX-AL: n = 9) (Fig. 1).

The body weight of rats was monitored daily during the period of treatment (D-5 to D9), then every 10 days. Moreover, food and water consumption was determined. The hematocrit (Ht) and plasma hydroperoxides concentration were evaluated over the all period of the study.

At the end of the study (D40; D70) the volume of abdominal ascites was measured and heart functional parameters were evaluated in vivo by left ventricular catheterization. Liver tissue samples were withdrawn for further histological analysis.

\subsection{Heart functional parameters measured in vivo}

The rats were anaesthetized with sodium thiopental $(60 \mathrm{mg} / \mathrm{kg}$, i.p.) and heparinized (500 IU/kg). After thorax depilation, a catheter connected to a pressure transducer, was inserted into the left ventricle through chest wall in order to measure heart rate (HR) and left ventricular pressures (left ventricular end-diastolic pressure: LVEDP, left ventricular systolic pressure: LVSP, left ventricular developed pressure: LVDP = LVSP-LVEDP) during the first minute of cardiac catheterization. Left ventricle contractility was expressed as $+\mathrm{dP} / \mathrm{dt}$ and left ventricle relaxation as $-\mathrm{dP} / \mathrm{dt}$.

At the end of the study the blood was taken by cardiac puncture, centrifuged and the plasma was immediately frozen into liquid nitrogen. Hearts were excised, segmented and frozen.

\subsection{Blood/plasma determinations}

\subsubsection{Hematocrit $(\mathrm{Ht})$}

The hematocrit (Ht, or erythrocyte volume fraction) of rats was measured before the injection of doxorubicin or alpha-lipoic acid (D-5), at the end of the treatment (D10) and every 15 days during period of rat's observation. For that purpose, a small quantity of blood was collected from 
the tail in a heparinized capillary tube and centrifuged to determine the proportion from blood volume that is occupied by red blood cells.

\subsubsection{Plasma lipid peroxidation}

Determination of plasma hydroperoxides using the "FORT” test.

The "FORT" test is a colorimetric test based on the ability of transition metals such as iron, to catalyze in the presence of hydroperoxides $(\mathrm{ROOH})$, the formation of free radicals (ex: RO•, ROO•) which are then trapped by a chemically amine derivative $\left(\mathrm{CrNH}_{2}\right)$. This amine reacts with free radicals forming a stable colored cation radical $\left(\mathrm{CrNH}_{2}{ }^{-+}\right)$which absorbance is measured at $505 \mathrm{~nm}$. The intensity of color is in direct correlation with the amount of free radical compounds (Beer Lambert Law) and, consequently, the oxidative level of the sample analyzed [33].

Hydroperoxides were measured in the plasma at D-5, D0, D10, D40 and D70.

\section{Determination of Thiobarbituric Acid Reactive Substances (TBARs).}

Measurement of plasma lipid peroxides was done by a colorimetric reaction with thiobarbituric acid. $1.5 \mathrm{ml}$ of trichloroacetic acid/thiobarbituric acid/hydrochloric acid solution was added to $500 \mu \mathrm{L}$ of plasma. The color of thiobarbituric acid pigment was developed in a water bath at $100^{\circ} \mathrm{C}$ for $15 \mathrm{mn}$. After cooling with ice to room temperature, $1 \mathrm{ml}$ of $70 \%$ trichloroacetic acid was added. After $1 \mathrm{~h} 30$, tubes were centrifuged and color of TBARs layers were measured at $553 \mathrm{~nm}$. The absorbance values were compared with a standard curve. Results were expressed in $\mu$ moles/g proteins; plasma protein was determined according to the method of Bradford [29]

Plasma TBARs were assessed only at the end of the study (D40; D70).

\subsubsection{Plasma ascorbyl free radical (AFR) determinations by electron spin resonance} (ESR) spectroscopy

$35 \mu \mathrm{L}$ of plasma samples were inserted into a quartz capillary tube which was placed in a HS cavity in order to analyze them at room temperature with a Bruker EMX-100 X-band spectrometer (Wissembourg, France). The following parameters were selected for optimal detection of AFR[34]: modulation frequency: $100 \mathrm{kHz}$, amplitude modulation: $0.8 \mathrm{G}$, microwave power: $40 \mathrm{~mW}$, microwave frequency: $8.5 \mathrm{GHz}$, conversion time: $40 \mathrm{~ms}$, time constant: $327 \mathrm{~ms}$, 


\subsection{Tissue determinations}

\subsubsection{Determination of cardiac Thiobarbituric Acid Reactive Substances (TBARs)}

Measurement of heart lipid peroxides was done by a colorimetric reaction with thiobarbituric acid. Hearts were homogenized in ice-cold phosphate buffered saline (0.05 M, pH 7). Then, 1.5 $\mathrm{ml}$ of trichloroacetic acid/thiobarbituric acid/hydrochloric acid solution was added. The color of thiobarbituric acid pigment was developed in a water bath at $100^{\circ} \mathrm{C}$ for $15 \mathrm{mn}$. After cooling to room temperature with ice, $1 \mathrm{ml}$ of $70 \%$ trichloroacetic acid was added. After $1 \mathrm{~h} 30$, tubes were centrifuged and color of TBARs layers were measured at $553 \mathrm{~nm}$. The absorbance values were compared with a standard curve. Results were expressed in $\mu \mathrm{M} / \mathrm{g}$ cardiac tissue.

\subsubsection{Superoxide Production by Fluorescence Histology}

In the presence of superoxide, ethidine, a fluorescent compound, is formed from dihydroethidium (DHE) and thus allows quantifying superoxide production. Frozen heart tissues were fixed for $10 \mathrm{mn}$ in acetone. Slides were incubated in a light-protected humidified chamber at room temperature with $\operatorname{DHE}(5 \mu \mathrm{M})$ for $5 \mathrm{mn}$. Slides were immediately analyzed with a computer-based digitizing image system (Microvision, France) using a fluorescent microscope (Eclipse 600, Nikon, France) connected to a video camera (TriCCD, Sony, France). Fluorescence was detected at $590 \mathrm{~nm}$ and carried forward to the nuclear number. Results were expressed in fluorescence intensity/nuclear number.

\subsection{Statistical analysis}

All data are expressed as means \pm S.E.M. To compare the groups, at 1 month or at 2 month after the end of treatment, statistical analyses were performed with the one-factor analysis of variance (ANOVA) test (SigmaStat); ANOVA was followed, if necessary, by a Newman Keuls test. To compare the evolution of parameters during the all period of study (period of treatment and period of rat's observation) we used a two-factor repeated measures analysis of variance (ANOVA) test (SigmaStat). Significance was established at a value of $P<0.05$. 


\section{Results}

Two rats of DOX-AL group died during the observational period (at day 26 and day 30 after the end of the treatment). A very high volume of abdominal ascites fluid was observed in these dead rats.

\subsection{Body weight and food consumption in rats}

Controls and lipoic acid-treated rats have gained in weight during all period of study (period of treatment and period of rat's observation). Doxorubicin induced a significant loss of rats' body weight starting from the $3^{\text {rd }}$ day of treatment. Lipoic acid associated with doxorubicin treatment was not able to counter this body weight loss. After interruption of treatment, there was a trend towards recovery of body weight in rats from DOX and DOX-AL groups with kinetics identical to these of rats from Control and AL groups (Fig. 2A).

As might be expected, we found in our study that rats' body weight and food consumption followed approximately the same trend (Fig. 2B). Regarding the quantity of water drunk, no significant differences were observed among the four groups of animals except during the $1^{\text {st }}$ and $4^{\text {th }}$ days after the end of the treatment where animals treated with doxorubicin drunk a lower quantity of water than control rats (data not shown).

Two months after the end of the treatment (D70) there was a greater body weight recovery in rats of DOX-AL group compared with DOX group but without increase of food consumption (Fig. 2A, 2B). However, it appears later that body weight gain in DOX-AL group was explained by the presence of a larger volume of abdominal ascites fluid (Table 1).

\subsection{Abdominal ascites fluid and liver histological analysis}

We noted that the volume of ascites fluid accumulated 1 month (D40) and 2 months (D70) after the end of the treatment was significantly higher in rats treated with doxorubicin alone or combined with alpha-lipoic acid (DOX -AL). It was also observed that the abdominal ascites fluid was greater in the DOX-AL group that in the DOX group (Table 1). Histological analysis showed the presence of condensation and sinusoidal dilation in liver tissues of rats treated with doxorubicin alone or in combination with lipoic acid (Table 2). 


\subsection{Heart weight, heart weight to body weight ratio}

Two months (D70) after the end of the treatment, doxorubicin alone or associated with alpha-lipoic acid induced a significant decrease of heart weight as compared to this of control or AL groups (Fig. 3A). Heart to body weight ratio, which estimates cardiac hypertrophy, was significantly $(\mathrm{P}<0.05)$ increased in DOX group (Fig. 3B).

\subsection{Cardiac parameters evaluated in vivo by left ventricle catheterization}

Heart rate (HR) was not influenced by doxorubicin treatment at D40 and D70. Left ventricular developed pressure (LVDP), $+\mathrm{dP} / \mathrm{dT}$ and $-\mathrm{dP} / \mathrm{dT}$ were not modified 1 month after the end of treatment (D40) but at D70, we observed in animals treated with doxorubicin alone (DOX) or in combination with alpha-lipoic acid (DOX-AL) a significant decrease $(\mathrm{P}=0.034)$ of $+\mathrm{dP} / \mathrm{dT}$ (Table 3).

\subsection{Blood/plasma parameters}

\subsubsection{Hematocrit $(\mathrm{Ht})$}

As shown in Figure 4, a cumulative dose of $10 \mathrm{mg} / \mathrm{kg}$ of doxorubicin over10 days (D10) induced a decrease in $\mathrm{Ht}$ values and the emergence of anemia in rats of DOX and DOX-AL groups. This anemia persisted 15 days (D25) after the end of the treatment. Subsequently during the period of animal's surveillance, Ht values were similar in the four groups of rats.

\subsubsection{Plasma hydroperoxides $(\mathrm{ROOH})$ concentration determined by the "FORT" test}

Ten days of treatment with alpha-lipoic acid $(50 \mathrm{mg} / \mathrm{kg} / \mathrm{day})$ induced a significant decrease of plasma hydroperoxides in AL group as compared to control group: (1.36 \pm 0.08 vs. $2.44 \pm 0.41 \mathrm{mmol} / 1 \mathrm{H}_{2} \mathrm{O}_{2}, \mathrm{P}<0.05$ ), which was noticeable only after 5 days of treatment in both AL-treated groups. A cumulative dose of $10 \mathrm{mg} / \mathrm{kg}$ of doxorubicin lead to an increase of $\mathrm{ROOH}$ in both DOX and DOX-AL groups in comparison to AL group. One month after the end of the treatment (D40), the rate of plasma hydroperoxides remained higher in animals treated with doxorubicin, but not 2 months after the end of the treatment (Fig. 5). 


\subsubsection{Plasma concentration of Thiobarbituric Acid Reactive Substances (TBARs)}

Two months after the end of the treatment, the plasma TBARs was significantly higher in the DOX-AL group as compared to Control and AL groups; while only a tendency $(\mathrm{P}=0.059)$ to increase TBARS values in DOX group was observed (Table 4).

\subsubsection{Ascorbate plasma concentrations}

One month after the end of the treatment, the plasma concentration of ascorbate was significantly reduced in DOX-AL group as compared to AL and Control groups. Two months after the end of the treatment (D70) the decrease of plasma concentrations of ascorbate was more evident in both groups of rats treated by doxorubicin: DOX and DOX-AL and associated with a significant increase of AFR to ascorbate ratio (Table 4).

\subsection{Tissue parameters \\ 3.6.1. Heart tissue TBARs}

Two months after the end of the treatment, there was a significant $(+50 \%, \mathrm{P}<0.01)$ increase of TBARs the heart of rats from DOX and DOX-AL groups (Table 3) compared with the values of C or LA heart tissue samples.

\subsubsection{Heart tissue superoxide anion production}

The production of superoxide anion $\left(\mathrm{O}_{2}{ }^{\bullet-}\right)$ assessed with DHE, revealed a higher oxidative stress in cardiac tissues of rats treated with doxorubicin alone (DOX) 1 month after the end of the treatment. Two months after the end of the treatment, the heart tissue production of $\mathrm{O}_{2}{ }^{--}$was significantly higher in both groups of rats treated with doxorubicin (DOX, 9.10 \pm 0.18 and DOX$\mathrm{AL}, 9.40 \pm 0.19)$ as compared to Control $(4.6 \pm 0.10)$ or AL $(4.7 \pm 0.1)$ groups (Table 4$)$. 


\section{Discussion}

The administration of a cumulative dose of $10 \mathrm{mg} / \mathrm{kg}$ doxorubicin induced a decrease in rats' body weight, associated with reduced food consumption. After the end of the treatment, during the two months of experimental design, a body weight and ingested food recovery was observed but did not reach values of Control group. Treatment with alpha-lipoic acid had no effect on the doxorubicin-induced anorexia. It is noteworthy that for rats treated with doxorubicin in combination with alpha-lipoic acid the higher weight recovery was not due to food ingestion but was secondary to a larger accumulation of ascites fluid, revealed and measured during rats' euthanasia. The presence of ascites fluid could be the consequence of cardiac, renal or liver impairment [35-36]. In our situation the hepatic and cardiac alterations were more obvious, as revealed by a higher degree of histological alterations in the liver of rats treated with doxorubicin and an alteration of heart contractility.

Besides anorexia, doxorubicin induced an anemia that persisted 15 days after the end of the treatment; subsequently, the hematocrit values returned to normal. The anemia is a frequent side-effect reported after chemotherapy.

Doxorubicin alone or combined with alpha-lipoic acid induced a decrease in heart weight 2 months after the end of treatment, happening sooner in rats treated with doxorubicin alone. This phenomenon has been described in other different studies [37-38] and could be explained by cardiomyocytes' apoptosis [39-41]. The heart to body weight ratio, a cardiac hypertrophy index, was increased 2 months after treatment in DOX group. In DOX-AL group this ratio was not significant, probably because of "artificial" increase of body weight due to ascites accumulation.

Cardiac functional parameters, measured in vivo in our experimental conditions, were affected 2 month after the treatment by a cumulative dose of $10 \mathrm{mg} / \mathrm{kg}$ doxorubicin, with a lower left ventricular contractility (+dP/dt) in DOX and DOW-AL hearts, inducing a non significant reduction of PDVG and of left ventricular relaxation index $(-\mathrm{d} P / \mathrm{d} t)$. As was already observed in our laboratory[42], the impairment of contractility is a very late event and is only at its beginnings two months after a cumulative dose of $10 \mathrm{mg} / \mathrm{kg}$ while the general condition of rats is so dramatically deteriorating that it threatens life and leads to high mortality. Sacco et al [37] have shown that a total cumulative dose of $7.5 \mathrm{mg}$ doxorubicin does not affect PDVG but decreases $+\mathrm{dP} / \mathrm{dt} 13$ weeks after the end of treatment. In fact, the heart contractility deterioration could become more evident after cardiac $\beta$-adrenergic stimulation with isoprenaline [37]. 
In our experimental conditions, the addition of alpha-lipoic acid to doxorubicin treatment did not prevent neither cardiac alteration nor degradation of general physical condition. Al-Majed et al [43] noted a cardioprotective effect of alpha-lipoic acid 48 hours after doxorubicin administration. While alpha-lipoic acid combined with doxorubicin might provide some protection few days after doxorubicin treatment, there are no studies to confirm or reject this cardioprotective effect at long term after the end of chemotherapy.

Regarding the assessment of plasma and cardiac oxidative stress, the methods used in this work were various and complex, each of them having some characteristics of sensitivity and specificity. Plasma lipid peroxidation was assessed as 1) plasma hydroperoxides concentration evaluated during the treatment and in the moment of rats' euthanasia and 2) plasma malonedialdehyde (MDA) concentration measured at the time of rats euthanasia ( 1 and 2 months after the end of treatment). We noted a significant decrease of hydroperoxides plasma levels after a cumulative dose of $250 \mathrm{mg} / \mathrm{kg}$ alpha-lipoic acid (5 days of treatment). This decrease was maintained until the end of treatment (15 days of treatment with a cumulative dose of $750 \mathrm{mg} / \mathrm{kg}$ alpha-lipoic acid) without evidence of a dose-effect relationship. In addition, a cumulative dose of $10 \mathrm{mg} / \mathrm{kg}$ doxorubicin (10 days of treatment) induced an increase in plasma hydroperoxides; the values were 2.5 times higher as compared to those obtained in AL group. These results are in favor of an early free radical circulating stress during doxorubicin treatment. On the other hand, 2 months after the end of treatment, plasma TBARs were significantly higher in rats treated with doxorubicin in combination with alpha-lipoic acid (DOX-AL group).

To get a better evaluation of plasma oxidative stress it was necessary to evaluate the levels of some antioxidant systems. Thus, we determined the plasma concentration of vitamin $\mathrm{C}$ by HPLC and the plasma ascorbyl radical level by electron paramagnetic resonance (EPR) spectroscopy. Two months after treatment, the plasma concentration of ascorbate was significantly lowered in rats treated with doxorubicin alone or in combination with alpha-lipoic acid. This phenomenon can be explained by a decrease in hepatic vitamin $C$ synthesis and by an excess of free radical species production as we previously reported [38].

Evaluation of cardiac oxidative stress by TBARs or by ethidine (DHE) fluorescence showed a significant increase of $\mathrm{O}_{2}{ }^{-}$production and of the malonedialdehyde levels in DOX and DOX-AL groups, 2 months after doxorubicin administration. In a similar study carried out in our laboratory, the cardiac oxidative stress was not evident 8 days after treatment with a commutative 
dose of $10 \mathrm{mg} / \mathrm{kg}$ doxorubicin [38]. This could confirm that tissue oxidative stress is a late event in the onset of doxorubicin cardiotoxicity.

It is important to note that, in our experimental conditions, the plasma or cardiac oxidative stress was not improved by the addition of alpha-lipoic acid to the doxorubicin treatment. Despite this, it is important to remember that alpha-lipoic acid alone significantly decreases the plasma hydroperoxides concentration but in combination with doxorubicin it had no beneficial effect. Contrary to our initial hypothesis, the results obtained regarding the mortality, the presence of high quantities of ascites and the hepatic alterations (morphologically and metabolically), indicate that the combination of doxorubicin with alpha-lipoic acid is rather deleterious than beneficial on the parameters evaluated.

In contrast to our results, some experimental studies showed that alpha-lipoic acid administered $24 \mathrm{~h}$ before the injection of adriamycin, once a week over a period of 10 to 12 weeks, had a beneficial effect in renal [44-45] and testicular toxicity [46], without mentioning majors side-effects. The lack of alpha-lipoic acid efficiency in preventing doxorubicin cardiotoxicity found in our study could be due to an inhibition of compensatory mechanisms activated at the start of chemotherapy. Indeed, there is a long period of time where no modifications in oxidative stress status and in cardiac contractile parameters appear. This latent period without symptoms might be secondary to the involvement of compensatory mechanisms that are quite early triggered [35, 47]. It is not easy to evaluate the specific pharmacologic actions of an antioxidant. For instance, it is known that antioxidants can prevent the cardioprotective mechanisms triggered by ischemic preconditioning, whereas administration of free radicalgenerating systems may mimic ischemic preconditioning [48-50]. It is worth mentioning, though, that in our protocol, the administration of alpha-lipoic acid was made 5 days prior to the introduction of doxorubicin. The reactive oxygen or nitrogen species formed after the first doses of anthracyclines might induce cellular protective pathways that are unfortunately overwhelmed lately by the following administrations of anthracycline. Then, pre-treatment with an antioxidant such as alpha-lipoic acid might paradoxically reinforce the toxic effects of doxorubicin, not only on the oxidative stress levels but also on cellular injury. In addition, a possible negative interaction between the two substances could not be excluded. Further work is obviously needed to confirm one of these hypotheses, exploring more thoroughly the timing of doxorubicin and alpha-lipoic acid administration or the dosages used. 


\section{Conclusion}

In conclusion, this study confirmed that the general state of animals is early altered by doxorubicin treatment while the cardiac problems and the plasma and tissue oxidative stress are more obvious two months after completion of the treatment. Contrary to our initial hypothesis, the administration of alpha-lipoic acid in combination with doxorubicin was not followed by a beneficial effect in the heart function or in the general oxidative stress, and led to a higher degradation of the hepatic function (ascites fluid accumulation). The antioxidant "beneficial" properties of alpha-lipoic acid appear clearly depending on the experimental conditions, and the cardioprotective potential of some antioxidant molecules in the context of chemotherapy should be carefully approached. 


\section{ACKNOWLEDGMENTS}

We wish to thank Philip Bastable for English assistance. 


\section{References}

[1] D.M. Green, Y.A. Grigoriev, B. Nan, J.R. Takashima, P.A. Norkool, G.J. D'Angio, N.E. Breslow, Congestive heart failure after treatment for Wilms' tumor: a report from the National Wilms' Tumor Study group, J Clin Oncol 19 (2001) 1926-1934.

[2] L.C. Kremer, E.C. van Dalen, M. Offringa, J. Ottenkamp, P.A. Voute, Anthracyclineinduced clinical heart failure in a cohort of 607 children: long-term follow-up study, J Clin Oncol 19 (2001) 191-196.

[3] R.E. Scully, S.E. Lipshultz, Anthracycline cardiotoxicity in long-term survivors of childhood cancer, Cardiovasc Toxicol 7 (2007) 122-128.

[4] A. Giantris, L. Abdurrahman, A. Hinkle, B. Asselin, S.E. Lipshultz, Anthracyclineinduced cardiotoxicity in children and young adults, Crit Rev Oncol Hematol 27 (1998) 53-68.

[5] S.E. Lipshultz, N. Rifai, V.M. Dalton, D.E. Levy, L.B. Silverman, S.R. Lipsitz, S.D. Colan, B.L. Asselin, R.D. Barr, L.A. Clavell, C.A. Hurwitz, A. Moghrabi, Y. Samson, M.A. Schorin, R.D. Gelber, S.E. Sallan, The effect of dexrazoxane on myocardial injury in doxorubicin-treated children with acute lymphoblastic leukemia, N Engl J Med 351 (2004) 145153.

[6] S.M. Swain, P. Vici, The current and future role of dexrazoxane as a cardioprotectant in anthracycline treatment: expert panel review, J Cancer Res Clin Oncol 130 (2004) 1-7.

[7] M. Tokarska-Schlattner, M. Zaugg, C. Zuppinger, T. Wallimann, U. Schlattner, New insights into doxorubicin-induced cardiotoxicity: the critical role of cellular energetics, J Mol Cell Cardiol 41 (2006) 389-405.

[8] G. Minotti, P. Menna, E. Salvatorelli, G. Cairo, L. Gianni, Anthracyclines: molecular advances and pharmacologic developments in antitumor activity and cardiotoxicity, Pharmacol Rev 56 (2004) 185-229.

[9] E.L. De Beer, A.E. Bottone, E.E. Voest, Doxorubicin and mechanical performance of cardiac trabeculae after acute and chronic treatment: a review, Eur J Pharmacol 415 (2001) 1-11.

[10] S. Delemasure, C. Vergely, M. Zeller, Y. Cottin, L. Rochette, [Preventing the cardiotoxic effects of anthracyclins. From basic concepts to clinical data], Ann Cardiol Angeiol (Paris) 55 (2006) 104-112.

[11] T. Simunek, M. Sterba, O. Popelova, M. Adamcova, R. Hrdina, V. Gersl, Anthracyclineinduced cardiotoxicity: overview of studies examining the roles of oxidative stress and free cellular iron, Pharmacol Rep 61 (2009) 154-171.

[12] M.I. Gharib, A.K. Burnett, Chemotherapy-induced cardiotoxicity: current practice and prospects of prophylaxis, Eur J Heart Fail 4 (2002) 235-242.

[13] N. Siveski-Iliskovic, M. Hill, D.A. Chow, P.K. Singal, Probucol protects against adriamycin cardiomyopathy without interfering with its antitumor effect, Circulation 91 (1995) $10-15$.

[14] C. Vergely, S. Delemasure, Y. Cottin, L. Rochette, Preventing the cardiotoxic effects of anthracyclines: from basic concepts to clinical data, Heart Metab. 35 (2007) 1-7.

[15] K.A. Wouters, L.C. Kremer, T.L. Miller, E.H. Herman, S.E. Lipshultz, Protecting against anthracycline-induced myocardial damage: a review of the most promising strategies, $\mathrm{Br} \mathrm{J}$ Haematol 131 (2005) 561-578.

[16] M. Marty, M. Espie, A. Llombart, A. Monnier, B.L. Rapoport, V. Stahalova, Multicenter randomized phase III study of the cardioprotective effect of dexrazoxane (Cardioxane) in 
advanced/metastatic breast cancer patients treated with anthracycline-based chemotherapy, Ann Oncol 17 (2006) 614-622.

[17] B. Anderson, Dexrazoxane for the prevention of cardiomyopathy in anthracycline treated pediatric cancer patients, Pediatr Blood Cancer 44 (2005) 584-588.

[18] L.R. Wiseman, C.M. Spencer, Dexrazoxane. A review of its use as a cardioprotective agent in patients receiving anthracycline-based chemotherapy, Drugs 56 (1998) 385-403.

[19] L. Elbl, H. Hrstkova, I. Tomaskova, J. Michalek, Late anthracycline cardiotoxicity protection by dexrazoxane (ICRF-187) in pediatric patients: echocardiographic follow-up, Support Care Cancer 14 (2006) 128-136.

[20] G.P. Biewenga, G.R. Haenen, A. Bast, The pharmacology of the antioxidant lipoic acid, Gen Pharmacol 29 (1997) 315-331.

[21] S. Ghibu, C. Richard, S. Delemasure, C. Vergely, C. Mogosan, A. Muresan, [An endogenous dithiol with antioxidant properties: alpha-lipoic acid, potential uses in cardiovascular diseases], Ann Cardiol Angeiol (Paris) 57 (2008) 161-165.

[22] J.M. May, Z.C. Qu, D.J. Nelson, Uptake and reduction of alpha-lipoic acid by human erythrocytes, Clin Biochem 40 (2007) 1135-1142.

[23] A. Bilska, L. Wlodek, Lipoic acid - the drug of the future?, Pharmacol Rep 57 (2005) 570-577.

[24] K.J. Cho, H. Moini, H.K. Shon, A.S. Chung, L. Packer, Alpha-lipoic acid decreases thiol reactivity of the insulin receptor and protein tyrosine phosphatase 1B in 3T3-L1 adipocytes, Biochem Pharmacol 66 (2003) 849-858.

[25] D. Ziegler, M. Hanefeld, K.J. Ruhnau, H. Hasche, M. Lobisch, K. Schutte, G. Kerum, R. Malessa, Treatment of symptomatic diabetic polyneuropathy with the antioxidant alpha-lipoic acid: a 7-month multicenter randomized controlled trial (ALADIN III Study). ALADIN III Study Group. Alpha-Lipoic Acid in Diabetic Neuropathy, Diabetes Care 22 (1999) 1296-1301.

[26] D. Ziegler, A. Ametov, A. Barinov, P.J. Dyck, I. Gurieva, P.A. Low, U. Munzel, N. Yakhno, I. Raz, M. Novosadova, J. Maus, R. Samigullin, Oral treatment with alpha-lipoic acid improves symptomatic diabetic polyneuropathy: the SYDNEY 2 trial, Diabetes Care 29 (2006) 2365-2370.

[27] T. Kunt, T. Forst, A. Wilhelm, H. Tritschler, A. Pfuetzner, O. Harzer, M. Engelbach, A. Zschaebitz, E. Stofft, J. Beyer, Alpha-lipoic acid reduces expression of vascular cell adhesion molecule-1 and endothelial adhesion of human monocytes after stimulation with advanced glycation end products, Clin Sci (Lond) 96 (1999) 75-82.

[28] W.J. Zhang, B. Frei, Alpha-lipoic acid inhibits TNF-alpha-induced NF-kappaB activation and adhesion molecule expression in human aortic endothelial cells, FASEB J 15 (2001) 24232432.

[29] S. Ghibu, B. Lauzier, S. Delemasure, S. Amoureux, P. Sicard, C. Vergely, A. Muresan, C. Mogosan, L. Rochette, Antioxidant properties of alpha-lipoic acid: effects on red blood membrane permeability and adaptation of isolated rat heart to reversible ischemia, Mol Cell Biochem 320 (2009) 141-148.

[30] L. Holmquist, G. Stuchbury, K. Berbaum, S. Muscat, S. Young, K. Hager, J. Engel, G. Munch, Lipoic acid as a novel treatment for Alzheimer's disease and related dementias, Pharmacol Ther 113 (2007) 154-164.

[31] U. Cakatay, Pro-oxidant actions of alpha-lipoic acid and dihydrolipoic acid, Med Hypotheses 66 (2006) 110-117.

[32] H. Moini, L. Packer, N.E. Saris, Antioxidant and prooxidant activities of alpha-lipoic acid and dihydrolipoic acid, Toxicol Appl Pharmacol 182 (2002) 84-90. 
[33] L. Lorgis, M. Zeller, G. Dentan, P. Sicard, C. Richard, P. Buffet, I. L'Huillier, J.C. Beer, Y. Cottin, L. Rochette, C. Vergely, The free oxygen radicals test (FORT) to assess circulating oxidative stress in patients with acute myocardial infarction, Atherosclerosis (2010).

[34] C. Vergely, V. Maupoil, M. Benderitter, L. Rochette, Influence of the severity of myocardial ischemia on the intensity of ascorbyl free radical release and on post-ischemic recovery during reperfusion, Free Radic Biol Med 24 (1998) 470-479.

[35] J. Robert, Preclinical assessment of anthracycline cardiotoxicity in laboratory animals: predictiveness and pitfalls, Cell Biol Toxicol 23 (2007) 27-37.

[36] K. Teraoka, M. Hirano, K. Yamaguchi, A. Yamashina, Progressive cardiac dysfunction in adriamycin-induced cardiomyopathy rats, Eur J Heart Fail 2 (2000) 373-378.

[37] G. Sacco, R. Giampietro, E. Salvatorelli, P. Menna, N. Bertani, G. Graiani, F. Animati, C. Goso, C.A. Maggi, S. Manzini, G. Minotti, Chronic cardiotoxicity of anticancer anthracyclines in the rat: role of secondary metabolites and reduced toxicity by a novel anthracycline with impaired metabolite formation and reactivity, Br J Pharmacol 139 (2003) 641-651.

[38] C. Richard, B. Lauzier, S. Delemasure, S. Talbot, S. Ghibu, B. Collin, J. Senecal, F. Menetrier, C. Vergely, R. Couture, L. Rochette, Effects of angiotensin-1 converting enzyme inhibition on oxidative stress and bradykinin receptor expression during doxorubicin-induced cardiomyopathy in rats, J Cardiovasc Pharmacol 52 (2008) 278-285.

[39] S.Y. Kim, S.J. Kim, B.J. Kim, S.Y. Rah, S.M. Chung, M.J. Im, U.H. Kim, Doxorubicininduced reactive oxygen species generation and intracellular $\mathrm{Ca} 2+$ increase are reciprocally modulated in rat cardiomyocytes, Exp Mol Med 38 (2006) 535-545.

[40] J.L. Reeve, E. Szegezdi, S.E. Logue, T.N. Chonghaile, T. O'Brien, T. Ritter, A. Samali, Distinct mechanisms of cardiomyocyte apoptosis induced by doxorubicin and hypoxia converge on mitochondria and are inhibited by Bcl-xL, J Cell Mol Med 11 (2007) 509-520.

[41] R.J. Bennink, M.J. van den Hoff, F.J. van Hemert, K.M. de Bruin, A.L. Spijkerboer, J.L. Vanderheyden, N. Steinmetz, B.L. van Eck-Smit, Annexin V imaging of acute doxorubicin cardiotoxicity (apoptosis) in rats, J Nucl Med 45 (2004) 842-848.

[42] C. Richard, B. Lauzier, S. Delemasure, S. Talbot, S. Ghibu, B. Collin, J. Senecal, F. Menetrier, C. Vergely, R. Couture, L. Rochette, Effects of angiotensin-1 converting enzyme inhibition on oxidative stress and bradykinin receptor expression during doxorubicin-induced cardiomyopathy in rats, J Cardiovas Pharmacol 52 (2008) 278-285.

[43] A.A. Al-Majed, A.M. Gdo, O.A. Al-Shabanah, M.A. Mansour, Alpha-lipoic acid ameliorates myocardial toxicity induced by doxorubicin, Pharmacol Res 46 (2002) 499-503.

[44] K.P. Malarkodi, A.V. Balachandar, P. Varalakshmi, Protective effect of lipoic acid on adriamycin induced lipid peroxidation in rat kidney, Mol Cell Biochem 247 (2003) 9-13.

[45] K.P. Malarkodi, A.V. Balachandar, P. Varalakshmi, The influence of lipoic acid on adriamycin induced nephrotoxicity in rats, Mol Cell Biochem 247 (2003) 15-22.

[46] C. Prahalathan, E. Selvakumar, P. Varalakshmi, Protective effect of lipoic acid on adriamycin-induced testicular toxicity, Clin Chim Acta 360 (2005) 160-166.

[47] A.T. Demiryurek, R.M. Wadsworth, Superoxide in the pulmonary circulation, Pharmacol Ther 84 (1999) 355-365.

[48] M. Osada, T. Sato, S. Komori, K. Tamura, Protective effect of preconditioning on reperfusion induced ventricular arrhythmias of isolated rat hearts, Cardiovasc Res 25 (1991) 441444.

[49] M.C. Toufektsian, S. Tanguy, A. Jeunet, J.G. de Leiris, F.R. Boucher, Role of reactive oxygen species in cardiac preconditioning: study with photoactivated Rose Bengal in isolated rat hearts, Free Radic Res 33 (2000) 393-405. 
[50] D.K. Das, N. Maulik, M. Sato, P.S. Ray, Reactive oxygen species function as second messenger during ischemic preconditioning of heart, Mol Cell Biochem 196 (1999) 59-67. 


\section{Legends to figures:}

Fig. 1: Experimental protocol. In control group $(\mathrm{C}, \mathrm{n}=18)$, rats received saline solution: 1 $\mathrm{ml} / \mathrm{kg}$ /day intraperitoneally (i.p.) during 15 days; from day -5 (D-5) to day 9 . In the doxorubicintreated group (DOX, $\mathrm{n}=18$ ), rats were injected i.p with $1 \mathrm{mg} / \mathrm{kg} /$ day doxorubicin during 10 days, from day D0 to D9. In the lipoic acid-treated group (AL), rats were injected i.p. with 50 $\mathrm{mg} / \mathrm{kg} /$ day alpha-lipoic acid during 15 days, from D-5 to D9. In the last group (DOX-AL, $\mathrm{n}=$ 18), rats were treated with both doxorubicin and alpha-lipoic acid at the same dose as the two previous groups. Rats were sacrificed one month (D40) or two months (D70) after the end of the treatment with doxorubicin or saline, and hematocrit $(\mathrm{Ht})$ was periodically measured.

Fig. 2: Evolution of body weight $[\mathrm{A}]$ and food consumption $[\mathrm{B}]$ in control group (C), alpha-lipoic acid group (AL), doxorubicin group (DOX) and doxorubicin + alpha-lipoic acid group (DOXAL) during all period of study $\left({ }^{*} \mathrm{P}<0.05,{ }^{* *} \mathrm{P}<0.01,{ }^{* * *} \mathrm{P}<0.001\right.$ : DOX and DOX-AL vs. C and AL; ${ }^{\& \&} \mathrm{P}<0.01:$ DOX vs. $\mathrm{C}$ and $\mathrm{AL} ;{ }^{\dagger} \mathrm{P}<0.05:$ DOX-AL vs. $\mathrm{C}$ and $\mathrm{AL} ;{ }^{\mathfrak{f}} \mathrm{P}<0.05{ }^{\mathfrak{f f}} \mathrm{P}<0.01$ : DOX-AL vs. DOX).

Fig. 3: Heart weight $[\mathrm{A}]$ and heart to body weight ratio [B] in control group (C), alpha-lipoic acid group (AL), doxorubicin group (DOX) and doxorubicin + alpha-lipoic acid group (DOX-AL), 2 months (D70) after the end of the treatment.

Fig. 4: Hematocrit evolution during all period of study, in control group (C), alpha-lipoic acid group (AL), doxorubicin group (DOX) and doxorubicin + alpha-lipoic acid group (DOX-AL) $\left({ }^{*} \mathrm{P}<0.05,{ }^{* *} \mathrm{P}<0.01:\right.$ DOX and DOX-AL vs. C and AL). 
Fig. 5: Plasma hydroperoxides $(\mathrm{ROOH})$ evolution during all period of study in control group (C), alpha-lipoic acid group (AL), doxorubicin group (DOX) and doxorubicin + alpha-lipoic acid group (DOX-AL). 
Table 1: Abdominal ascites fluid determined 1 month (D40) and 2 months (D70) after the end of the treatment in control group (C), alpha-lipoic acid group (AL), doxorubicin group (DOX) and doxorubicin + alpha-lipoic acid group (DOX-AL) $\left({ }^{* *} \mathrm{P}<0.01,{ }^{* * *} \mathrm{P}<0.001\right.$ : DOX and DOX-AL vs. C and AL).

\section{Number of rats which have developed abdominal} ascites in each group and volume of ascites $(\mathrm{ml})$.

\begin{tabular}{ccc} 
& $\mathbf{1}$ month & 2 months \\
\cline { 2 - 3 } $\mathbf{C}$ & $0 / 9$ & $0 / 9$ \\
$\mathbf{A L}$ & $0.32 \pm 0.08$ & $0.23 \pm 0.02$ \\
& $0 / 9$ & $0 / 9$ \\
DOX & $0.31 \pm 0.04$ & $0.30 \pm 0.03$ \\
& $8 / 9$ & $9 / 9$ \\
DOX-AL & $6.52 \pm 2.67^{* * * *}$ & $1.01 \pm 0.23^{* *}$ \\
& $7 / 7$ & $9 / 9$ \\
& $19.16 \pm 3.87^{* * *}$ & $57.47 \pm 24.6^{* * * *}$ \\
\hline
\end{tabular}


Table 2: Histological analysis of liver tissues collected 2 months (D70) after the end of the treatment in control group (C), alpha-lipoic acid group (AL), doxorubicin group (DOX) and doxorubicin + alpha-lipoic acid group (DOX-AL)

\begin{tabular}{ccccccc}
\hline & \multicolumn{5}{c}{ Histological tissue modifications } \\
\cline { 2 - 6 } & Condensation & Necrosis & $\begin{array}{c}\text { Sinusoidal } \\
\text { dilation }\end{array}$ & Inflammation & Neo-ductules & Thrombosis \\
\hline $\mathbf{C}$ & $0 / 2$ & $0 / 2$ & $0 / 2$ & $1 / 2$ & $0 / 2$ & $0 / 2$ \\
AL & $0 / 2$ & $0 / 2$ & $0 / 2$ & $1 / 2$ & $0 / 2$ & $0 / 2$ \\
DOX & $2 / 2$ & $1 / 2$ & $2 / 2$ & $0 / 2$ & $0 / 2$ & $0 / 2$ \\
DOX-AL & $2 / 2$ & $0 / 2$ & $2 / 2$ & $0 / 2$ & $0 / 2$ & $0 / 2$ \\
\hline
\end{tabular}


Table 3: Heart parameters evaluated in vivo by left ventricle catheterization in control group (C), alpha-lipoic acid group (AL), doxorubicin group (DOX) and doxorubicin + alpha-lipoic acid group (DOX-AL), 1 month (D40) and 2 months (D70) after the end of the treatment $\left({ }^{*} \mathrm{P}<0.05\right.$ : DOX and DOX-AL vs. C)

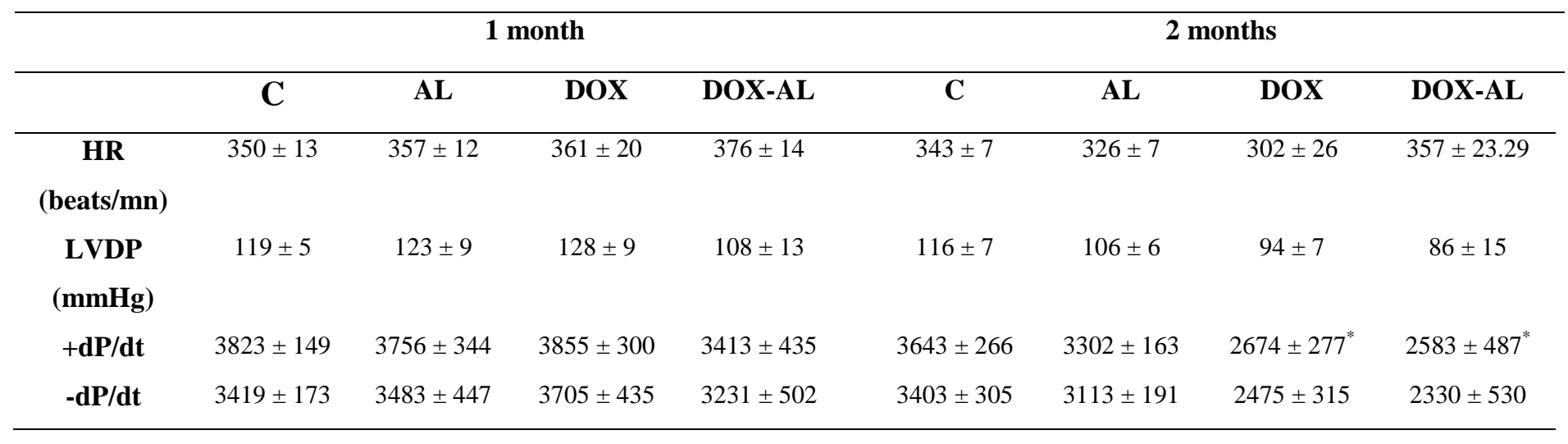


Table 4: Plasma and cardiac oxidative stress parameters evaluated 1 month (D40) and 2 months (D70) after the end of the treatment in control group (C), alpha-lipoic acid group (AL), doxorubicin group (DOX) and doxorubicin + alpha-lipoic acid group (DOX-AL) $\left({ }^{*} \mathrm{P}<0.05,{ }^{* *} \mathrm{P}<0.01\right.$ : DOX and DOX-AL vs. $\mathrm{C} ;{ }^{\dagger} \mathrm{P}<0.05,{ }^{\dagger \dagger} \mathrm{P}<0.01$ : DOX and DOX-AL vs. AL)

\begin{tabular}{|c|c|c|c|c|c|c|c|c|}
\hline & \multicolumn{4}{|c|}{1 month } & \multicolumn{4}{|c|}{2 months } \\
\hline & $\mathbf{C}$ & $\mathbf{A L}$ & DOX & DOX-AL & $\mathbf{C}$ & $\mathbf{A L}$ & DOX & DOX-AL \\
\hline $\begin{array}{c}\text { Plasma TBARs } \\
(\mu \text { moles/g protein) }\end{array}$ & $0.020 \pm 0.001$ & $0.022 \pm 0.001$ & $0.024 \pm 0.002$ & $0.027 \pm 0.003$ & $0.022 \pm 0.001$ & $0.023 \pm 0.001$ & $0.027 \pm 0.001$ & $0.034 \pm 0.003^{*}$ \\
\hline $\begin{array}{l}\text { Ascorbate } \\
\qquad(\mu \mathrm{M})\end{array}$ & $43.7 \pm 4.1$ & $42.8 \pm 2.8$ & $38.1 \pm 4.7$ & $27.0 \pm 4.6^{*}$ & $42.4 \pm 3.6$ & $39.3 \pm 4.9$ & $22.6 \pm 2.1^{* *+\dagger}$ & $22.9 \pm 5.0^{* * \dagger \dagger}$ \\
\hline $\begin{array}{c}\text { AFR/Ascorbate } \\
(\mathrm{AU}) /(\mu \mathrm{M})\end{array}$ & $0.063 \pm 0.003$ & $0.065 \pm 0.007$ & $0.080 \pm 0.019$ & $0.084 \pm 0.006$ & $0.051 \pm 0.004$ & $0.054 \pm 0.004$ & $0.073 \pm 0.006^{*}$ & $0.071 \pm 0.008^{*}$ \\
\hline $\begin{array}{c}\text { Tissular TBARs } \\
(\mu \mathrm{M} / \mathrm{g} \text { cardiac tissue })\end{array}$ & $19.6 \pm 1.9$ & $16.1 \pm 1.4$ & $19.4 \pm 1.8$ & $21.9 \pm 2.4$ & $13.9 \pm 1.4$ & $15.9 \pm 1.6$ & $21.7 \pm 3.3^{* *+\dagger}$ & $26.1 \pm 2.2^{* *+\dagger}$ \\
\hline $\begin{array}{c}\text { DHE } 10^{4} \\
\text { (\% fluorescence/nucleus) }\end{array}$ & $3.10 \pm 0.74$ & $2.70 \pm 0.74$ & $7.90 \pm 0.25^{*}$ & $4.90 \pm 0.68$ & $4.60 \pm 0.10$ & $4.70 \pm 0.11$ & $9.10 \pm 0.18^{* \dagger}$ & $9.40 \pm 0.19^{* \dagger}$ \\
\hline
\end{tabular}



Figure
Click here to download high resolution image

Figure 1

C:

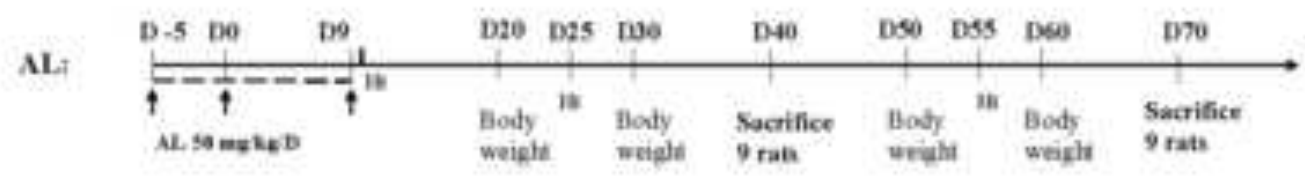

DOX:

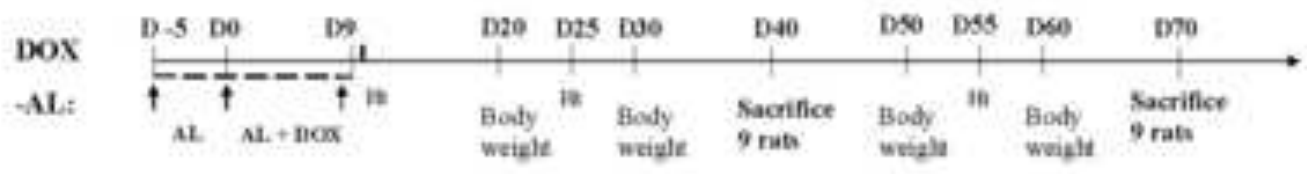


Figure
Click here to download high resolution image

Figure 2

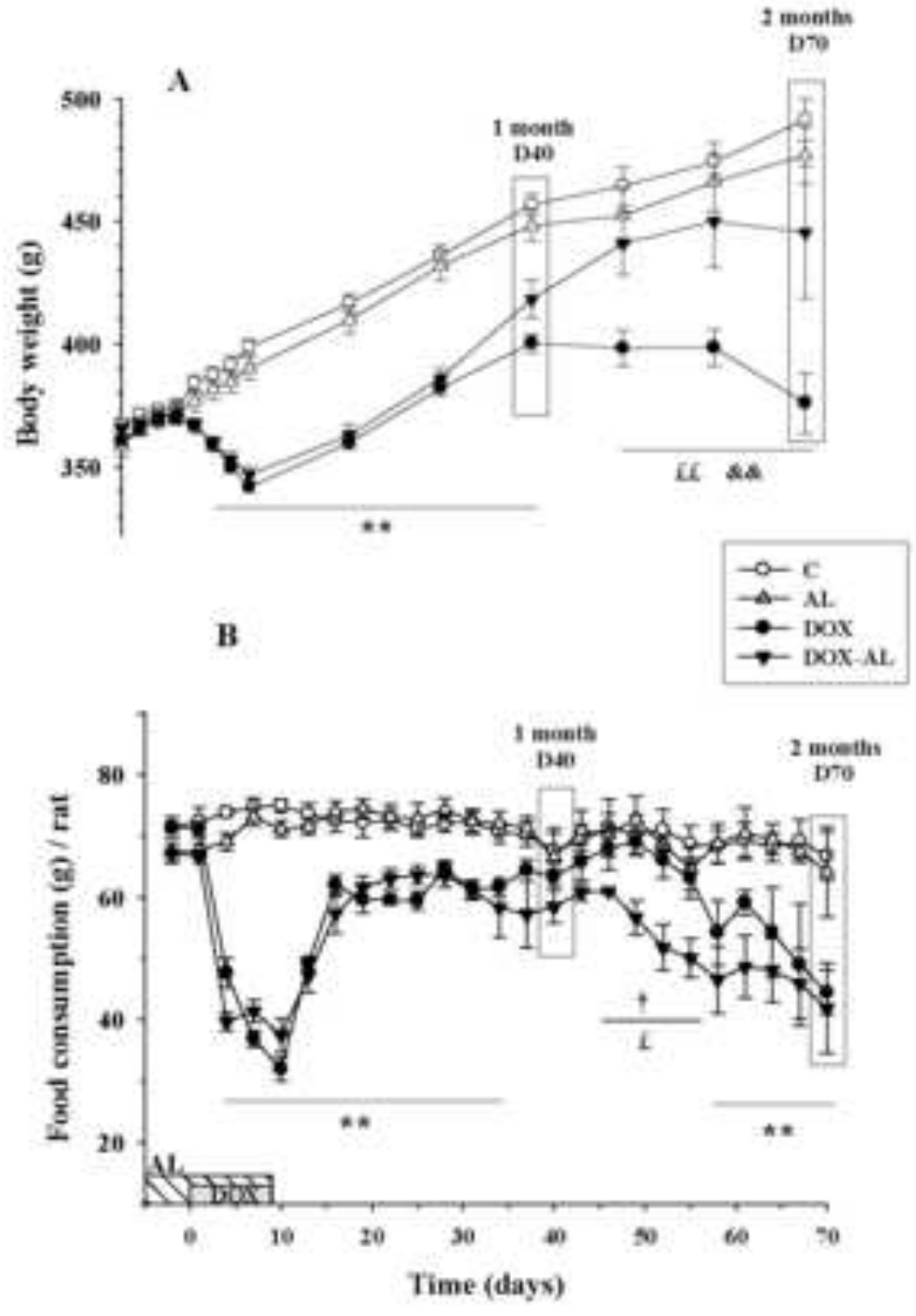


Figure
Click here to download high resolution image

Figure 3

A

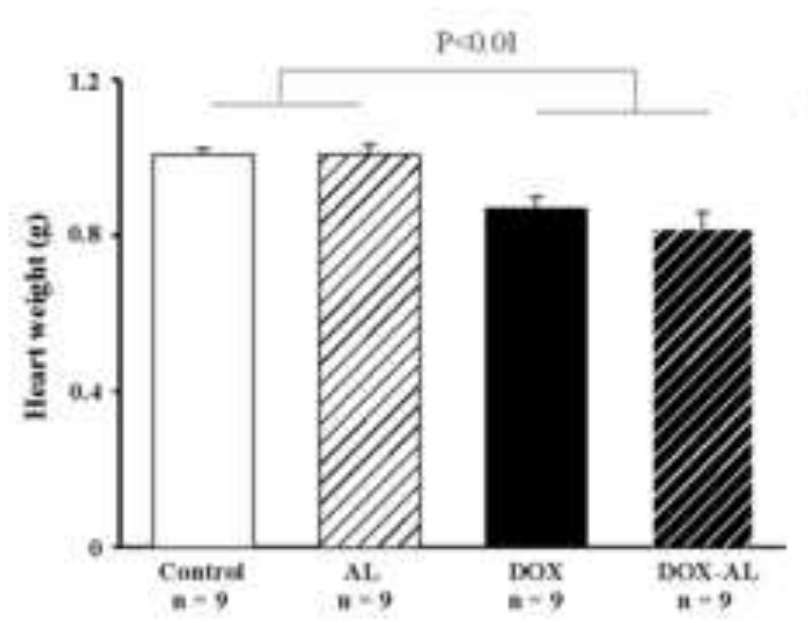

H

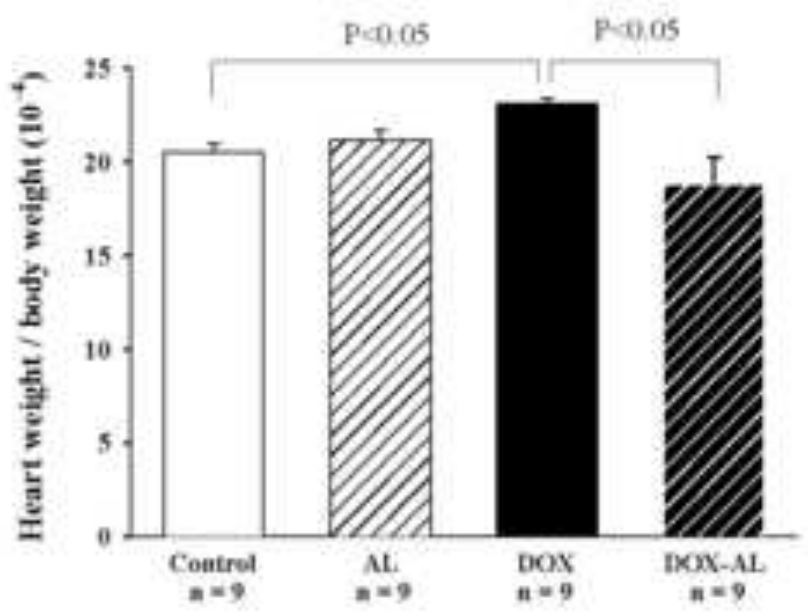


Figure
Click here to download high resolution image

Figure 4

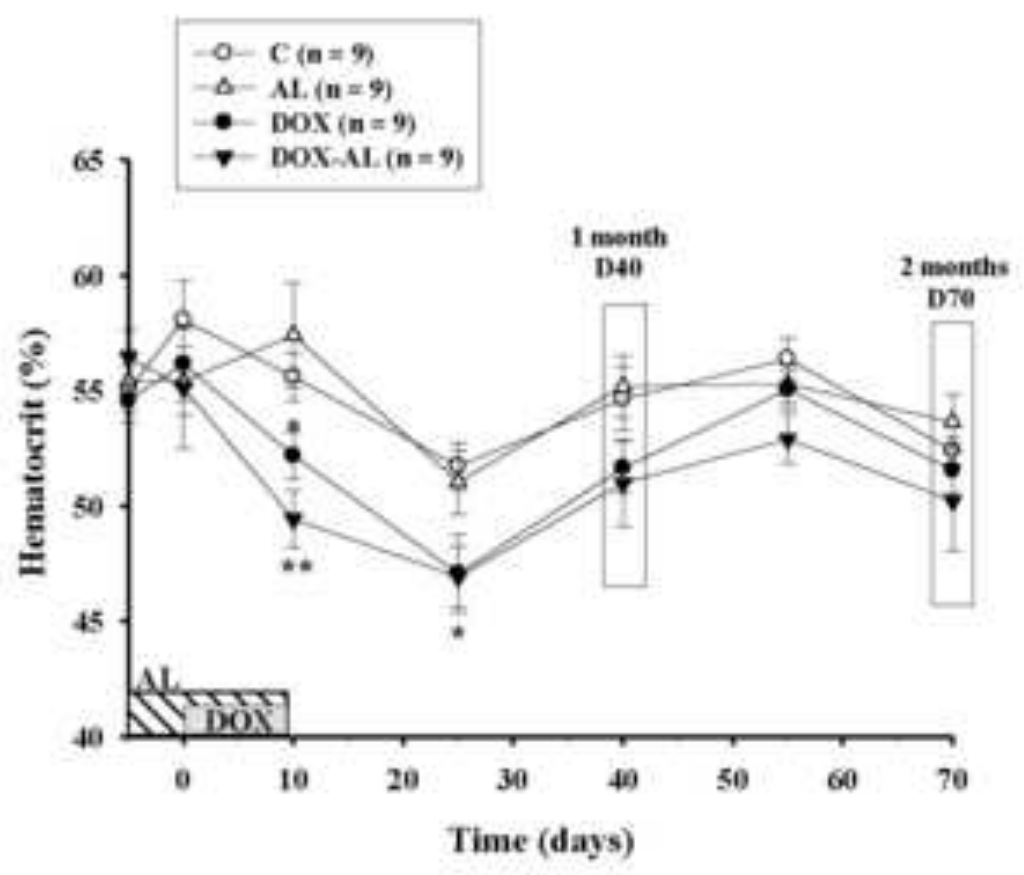


Figure
Click here to download high resolution image

Figure 5

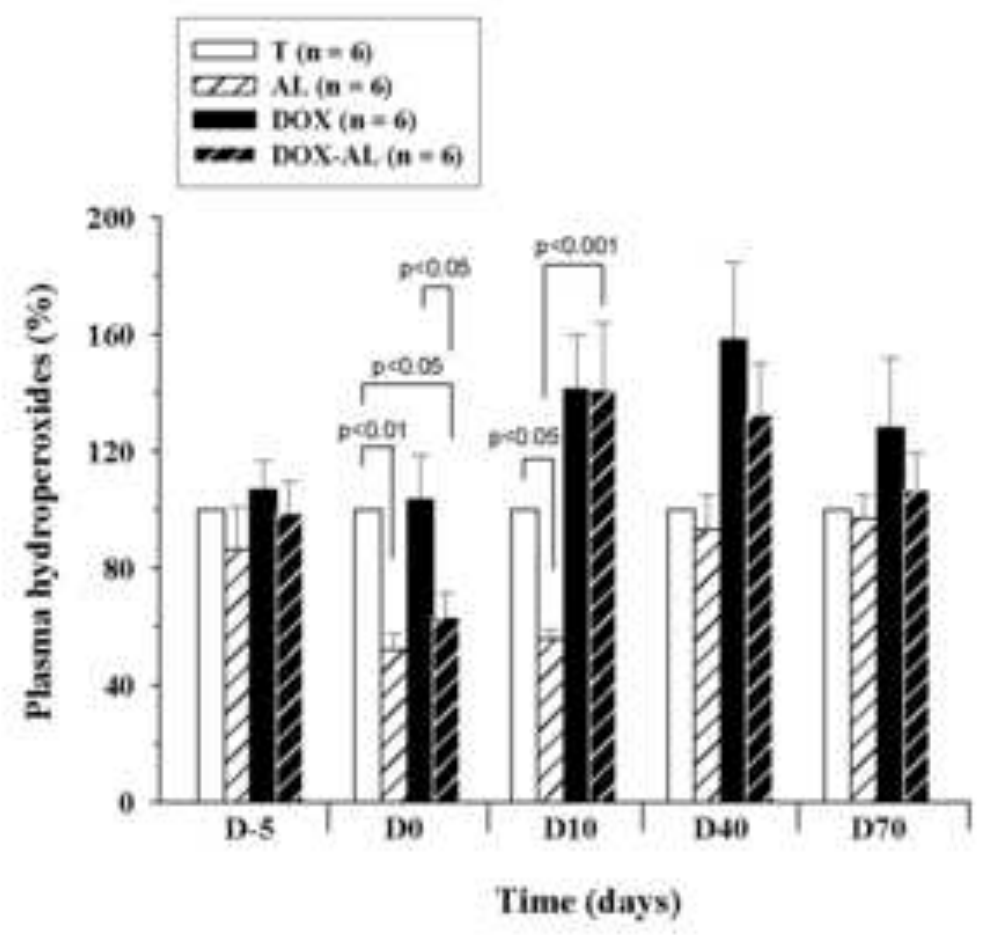

